\section{Desvendando barreiras de gênero no acesso de adolescentes à informação sobre saúde sexual e reprodutiva na Venezuela}

\author{
Unveiling gender barriers to adolescents' access \\ to information on sexual and reproductive \\ health in Venezuela
}

\section{Desvelando barreras de género en el acceso de adolescentes a la información sobre salud sexual y reproductiva en Venezuela}

\section{Resumo}

O objetivo foi analisar os discursos de adolescentes e profissionais de saúde em um estado da Venezuela acerca do acesso desta população à informação sobre saúde sexual e reprodutiva. Realizaram-se 12 entrevistas com adolescentes e 12 com profissionais, trabalhadas com a Análise de Discurso Crítica de Fairclough. Os resultados estruturaram-se em 3 temas: desigualdades de gênero; estratégias utilizadas pelos adolescentes e dificuldades dos serviços de saúde. Nos argumentos identificados, observa-se que a cultura das famílias matricentradas limita o acesso das meninas à informação sobre saúde sexual. Das meninas e dos adolescentes homossexuais, exige-se maior esforço no acesso à informação. Ambos os grupos procuram serviços fora de sua área de residência por temor à família ou por não confiar no sigilo profissional. As fontes privilegiadas pelos adolescentes para obter informação são: amigos e Internet. Um dos principais desafios é reconhecer os dispositivos institucionais que atuam na sociedade venezuelana, com maior força nas relações de poder na família, na escola e serviços de saúde. Tais barreiras reforçam o sexual double standard, perpetuando modelos de dominação patriarcal. Sua naturalização possibilita uma reprodução silenciosa de crenças/atitudes, provocando desigualdades de gênero no acesso aos serviços de saúde. As mudanças na prestação dos serviços oferecidos para adolescentes envolveriam renegociação das posições subjetivas tradicionais na interação profissional-usuário e desconstrução das relações de poder. É com participação de novas gerações de adolescentes, profissionais, pais, professores, produzindo discursos e normas de gênero mais equitativas, que possíveis mudanças serão engendradas.

Adolescente; Identidade de Gênero; Serviços de Saúde; Equidade no Acesso aos Serviços de Saúde; Saúde Sexual
Henny Luz Heredia-Martínez 1

Elizabeth Artmann 2

Marcos Nascimento 3

doi: 10.1590/0102-311X00193918

\section{Correspondência}

H. L. Heredia-Martínez

Instituto de Altos Estudios “Dr. Arnoldo Gabaldon".

Av. Bermúdez Sue, Maracay / Aragua 2101, Venezuela.

hennyluzhm@hotmail.com

1 Instituto de Altos Estudios "Dr. Arnoldo Gabaldon", Maracay, Venezuela.

2 Escola Nacional de Saúde Pública Sergio Arouca, Fundação Oswaldo Cruz, Rio de Janeiro, Brasil.

3 Instituto Nacional de Saúde da Mulher, da Criança e do Adolescente Fernandes Figueira, Fundação Oswaldo Cruz, Rio de Janeiro, Brasil. 


\section{Introdução}

A Venezuela, de 1999 a 2012, ocupou o primeiro lugar na taxa de fecundidade adolescente (101 por 1.000 adolescentes entre 15-19 anos) na América Latina e Caribe 1. Essa taxa diminuiu em 6 pontos entre 2006-2015 2, mantendo-se, contudo, sem variação de 2015 até 2017 3. O país ainda está entre os que têm as maiores taxas da região. O aumento nos casos de infecções sexualmente transmissíveis (IST) e HIV afeta a população adolescente. Para 2010, o grupo de 15-19 anos concentrou 20\% dos casos de IST com $22 \%$ em meninos e $17 \%$ em meninas. Apesar de não existirem estudos nacionais sobre a prevalência do HIV e outras IST em adolescentes no último decênio, estima-se que em 2009, das novas infeções por HIV, 50\% foram em adolescentes e jovens menores de 24 anos, atingindo em maior número às meninas 4 . Ainda persistem os problemas de acesso a preservativos e métodos contraceptivos 5 .

Os adolescentes de 10-19 anos representavam 18\% (5.558.445) do total da população venezuelana (31.431.164) em 2017 6. A Lei Orgânica para a Proteção de Crianças e Adolescentes (2015) 7 outorga cidadania e garantia plena de direitos às crianças e adolescentes. No artigo 50, a Saúde Sexual e Reprodutiva surge como estratégia integral e estabelece o direito à informação em saúde sexual e reprodutiva "segundo seu desenvolvimento", garantindo serviços acessíveis e confidenciais 7.

No Ministério do Poder Popular para a Saúde, a atenção diferenciada segundo necessidades específicas das/dos adolescentes é regulamentada na Norma Oficial para a Atenção Integral em Saúde Sexual e Reprodutiva, no subprojeto de "Saúde Sexual e Reprodutiva na Adolescência", com seis áreas de intervenção, sendo uma delas sobre informação, educação e comunicação em 5 .

As desigualdades no acesso das/dos adolescentes à informação sobre saúde sexual reprodutiva persistem na rede de serviços públicos de saúde, nas instituições educativas e nas famílias 8,9,10, apesar das estratégias intersetoriais implementadas a partir dos anos 2000 5,7. A sistematização e análises dessas desigualdades ainda constitui uma importante lacuna de conhecimento a ser preenchida no país.

Diante desse contexto, este artigo se propõe a analisar os discursos de adolescentes e profissionais das equipes básicas de saúde em um estado da Venezuela, acerca do acesso da população adolescente à informação sobre saúde sexual e reprodutiva e seus efeitos nas práticas dos serviços de saúde.

\section{Metodologia}

O estado Nueva Esparta na Venezuela foi selecionado por ter todas as áreas de responsabilidade definidas e as equipes básicas de saúde (EBS) organizadas (médicos, enfermeiras/auxiliares de enfermagem e promotores de saúde), embora não completas 11. Três municípios foram trabalhados: Mariño, por ser o que tem melhor acesso geográfico e onde se concentra $20 \%$ da população adolescente 6 ; Tubores e Península de Macanao, por conformarem a Área de Saúde Integral Comunitária de mais difícil acesso geográfico ${ }^{11}$. Os participantes da pesquisa foram as/os adolescentes representando o lugar do sujeito na população usuária e os profissionais das EBS, representando o lugar do sujeito serviços de saúde.

Para constituir o corpus de análise, desenharam-se dois roteiros semiestruturados de entrevistas que consideraram um conjunto de questões sobre os elementos que facilitam ou obstaculizam o acesso das/dos adolescentes à informação sobre saúde sexual e reprodutiva. O primeiro roteiro foi utilizado com as/os adolescentes. Para a seleção deles, foram considerados os critérios: ambos os sexos, entre 10 e 19 anos 12, usuários e não usuários dos serviços de saúde para garantir as diferentes experiências. Pelo conceito de saturação teórica 13, definiu-se um total de 12 entrevistas com seis meninas e seis meninos (sete de Mariño, três de Península de Macanao e dois de Tubores).

O segundo roteiro foi aplicado a médicos, enfermeiras/auxiliares de enfermagem e promotores de saúde das EBS, com pelo menos seis meses trabalhando no estabelecimento de saúde. Para garantir a participação dos diferentes tipos de profissionais das EBS, segundo os níveis do sistema, foram entrevistados 4 médicos, 4 enfermeiras e 4 promotores de saúde (dois do primeiro nível de atenção, um do segundo e um do terceiro), para um total de 12 entrevistas, sendo quatro por município. Todas as entrevistas se realizaram entre setembro/outubro de 2017. 
Este artigo fez parte de uma pesquisa em que se analisaram as dimensões do acesso das/dos adolescentes aos serviços de saúde e na qual se trabalhou com uma amostra de 246 adolescentes e 35 profissionais dos três municípios. Por essa amostra, foram selecionados as/os 12 adolescentes e os 12 profissionais, segundo as características anteriormente assinaladas.

Para trabalhar os resultados, optou-se pela Análise de Discurso Crítica (ADC) de Fairclough 14 que enfatiza a compreensão das relações entre desigualdades sociais e as formas como os textos são utilizados para denotar poder e ideologia. $\mathrm{O}$ autor propõe um modelo com três dimensões analíticas do discurso. A primeira é o texto que inclui as categorias da análise textual. A segunda é a prática discursiva, pela qual se analisam as atividades cognitivas de produção, distribuição, consumo do texto, como também o contexto, a força, a coerência, a intertextualidade e a intercursividade. A terceira é a prática social, relacionada com a ideologia e a hegemonia na instância discursiva analisada 14 .

Os resultados foram estruturados por temas e, valendo-se dos elementos textuais, realizaram-se análises de coerência e coesão. Identificaram-se a estrutura da argumentação dos enunciados, a forma de relação das orações e sua racionalidade. Identificaram-se os dispositivos analíticos: metáfora, interdiscursividade, ironia, negação e modalidade, para aproximar o objeto discursivo do processo social onde é produzido, e passar do objeto discursivo para o processo discursivo.

As entrevistas gravadas foram transcritas, mantendo-se a expressão fiel do espanhol falado com a finalidade de preservar todas as partículas discursivas e manter os sentidos produzidos na enunciação. As referências às entrevistas foram codificadas: EP (Entrevistas com Profissionais), EA (Entrevistas com as/os Adolescentes) e numeradas.

O estudo foi aprovado pelo Comitê de Ética da Direção de Pesquisa do Instituto de Altos Estudos "Dr. Arnoldo Gabaldon" do Ministério do Poder Popular para a Saúde da Venezuela, em 3 de abril de 2017 sob o número 003/2017 e pela Direção Estadual de Saúde do Estado Nueva Esparta em 12 de abril de 2017. O Termo de Consentimento Livre Esclarecido foi assinado pelos adolescentes com prévia autorização dos pais/representantes e pelos profissionais que aceitaram participar da pesquisa.

\section{Contexto enunciativo}

Em 2016, foi lançada a estratégia “100\% cobertura” no primeiro nível de atendimento, buscando garantir médicos nos consultórios populares. Porém, observa-se alta rotatividade e um número insuficiente de enfermeiros e promotores de saúde para atender às demandas 11. Mesmo com a ampliação da cobertura em 2016-2017, o Programa de Saúde do Adolescente (PSA) do Ministério do Poder Popular para a Saúde funcionava em 2017 com presença limitada no nível estadual: das 24 entidades federais, só 14 tinham ao menos uma consulta diferenciada para adolescentes, com percentuais de cobertura baixos. A crise econômica agravou os problemas já existentes de infraestrutura, escassez de medicamentos preservativos e métodos contraceptivos. Apesar do estabelecido na legislação venezuelana e dos esforços efetuados pelo Ministério do Poder Popular para a Saúde, a população adolescente continua sendo uma das menos priorizadas no sistema de saúde.

Dentre as principais condições jurídicas das/dos adolescentes, destacam-se: maioridade a partir dos 18 anos; responsabilidade legal por delitos a partir de 12 anos; idade para atendimento nos serviços de saúde sexual e reprodutiva sem pais/representante, 15 anos; idade de consentimento para relações sexuais, 16 anos e matrimônio/união civil com o consentimento dos pais/tutores/juízes, 16 anos para meninos e 14 para meninas 7 . O artigo 435 do Código Penal proíbe o aborto em suas diversas formas, exceto quando há risco para a vida da mulher 15. 


\section{Resultados e discussão}

Todas as enunciações discursivas, organizadas por temas e trechos numerados são apresentadas no Quadro 1.

\section{Quadro 1}

Enunciações discursivas de adolescentes e profissionais sobre o acesso dos adolescentes à informação sobre saúde sexual e reprodutiva. Nueva Esparta, Venezuela, 2017.

\begin{tabular}{|c|c|c|}
\hline Temas & Trechos dos adolescentes & Trechos dos profissionais \\
\hline $\begin{array}{l}\text { 1. Sexualidade dos } \\
\text { e das adolescentes: } \\
\text { um "tabu" que produz } \\
\text { desigualdades no acesso } \\
\text { à informação em saúde } \\
\text { sexual e reprodutiva. }\end{array}$ & 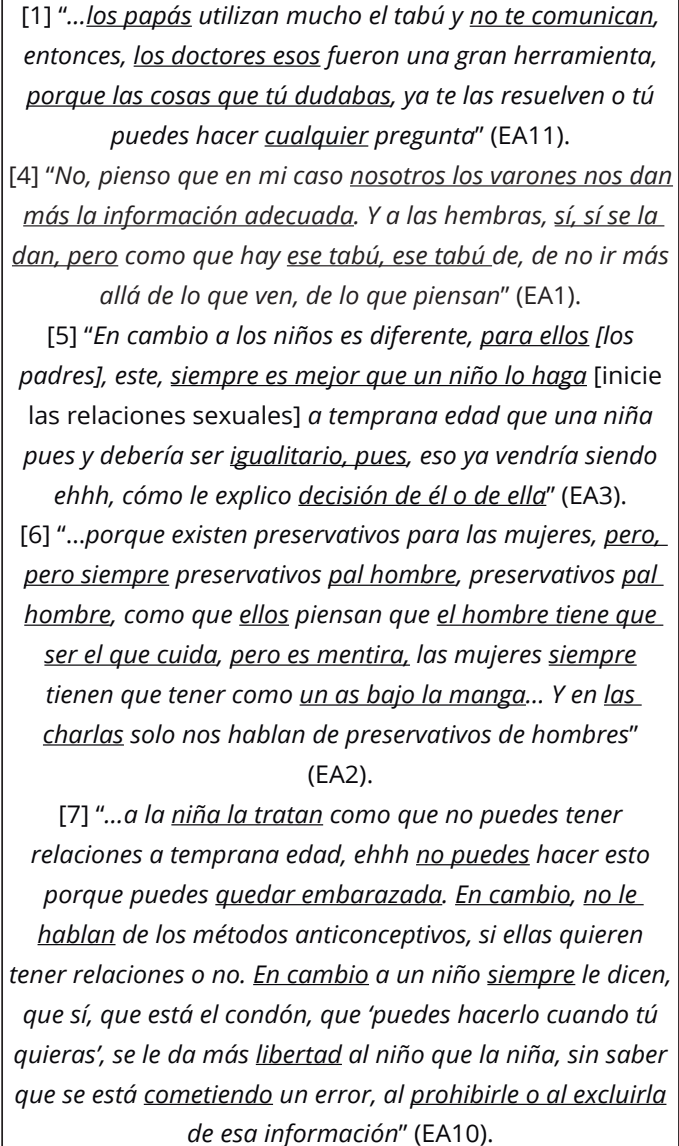 & $\begin{array}{l}\text { [2] "No, nada que ver, nada que ver, de hecho hay madres que } \\
\text { vienen buscando sus preservativos para sus hijos, iuju!, ipara } \\
\text { los varones! pero tienen hijas y no las traen..., ni ellas se lo } \\
\text { explican, ni las traen, porque les da pena, por la sociedad, por } \\
\underline{\text { el qué dirán y lo mal visto que está que una mujer empiece a }} \\
\text { tener relaciones, tempranas... para ellas [las madres] es sólo el } \\
\text { preservativo para los hombres que son los que pueden pues. } \\
\text { Es muy difícil" (EP10). } \\
\text { [3] "Noooo, eso es un tabú que es algo que es malísimo, } \\
\text { que "mi niña, mi hija, noooo", es algo que sigue siendo una } \\
\underline{\text { barrera que yo la he visto,... en más del 80\% de los casos que }} \\
\text { es alarmante, porque eso es salud, la sexualidad es parte } \\
\text { de la vida humana, que es normal, pero está el miedo de la } \\
\text { mamá,... "no, ella va a ser monja toda la vida" porque me lo } \\
\text { dicen y da miedo porque eso no es normal" (EP6). }\end{array}$ \\
\hline
\end{tabular}

(continua) 


\begin{abstract}
2. "Yo no quiero venir con mi mamá": estratégias dos adolescentes para ter acesso à informação sobre saúde sexual e
\end{abstract} reprodutiva.
[12] "...la mayoría de los papás actualmente son del otro siglo y me supongo nuestros abuelos, no les hablaban de eso, entonces ellos [los padres] quieren llevar como ese ciclo, ...también en cuanto a otros temas como la homosexualidad ...porque no les gusta hablar, porque no quieren que tú lo hagas" (EA6).

[14] "...si no lo hablan, ellos [los padres] piensan que tú no lo vas a hacer y no es así, más bien lo hacen más. Y si tú no me dices busco la información por otro lado información errónea, voy y lo hago yyy después es que vienen las consecuencias... buscamos en Internet o con los amigos, porque siempre hay un amigo más avispado que el otro y te cuenta y te dice, mira sí esto se hace así, hazlo, que eso no falla" (EA6).

[16] "Pienso que al recibir información de un adulto o de alguien así, la aceptamos, pero no la aceptamos de igual manera que de alguien que sea apegado a nosotros, un amigo que nos la de" (EA4).
[8] “...pero en la niña, el tabú, siempre el tabú, incluso ellas [las adolescentes] prefieren venir solas y me lo dicen ' $\underline{Y}_{0}$ no quiero venir con mi mamá y voy al ginecólogo con mi mamá y me siento mal porque le miento al ginecólogo' eso me ha pasado aquí, incluso ya te estoy hablando entre 16, 17 años, incluso en la etapa limítrofe entre 18 y 19" (EP6).

[9] "...siempre recibo muchachos y muchachas solas, sobre todo los que tienen una tendencia distinta, los que son homosexuales, vienen solos, o con el novio, pero con los padres JAMÁS, porque muchos ni siquiera le han dicho que son homosexuales o muchos de sus padres no le aceptan, ni le respetan eso, entonces ellos vienen solos a buscar

información, o ayuda, o preservativos u orientación porque se sienten mal o creen tener una enfermedad..." (EP4). [10] "Y entonces se han visto casos que cuando él dice [el adolescente] que es con un hombre [con quien tuvo relaciones sexuales], el familiar se desquicia" (EP12). [11] “...sencillamente somos humanos y ellos también son humanos [los adolescentes], no es que son extraterrestres en esa etapa de la vida... Y que la sexualidad es parte del ser humano... incluso la parte homosexual, eso se está juzgando mucho e incluso se puede ver familias rotas por esas causas que, no es justo" (EP6).

[13] "Sí, yo pienso que ellos [los adolescentes] se preocupan mucho por el tema a ser juzgados o a ser castigados. ...cuando vienen a pedirme anticonceptivos, en el caso de las chicas, vienen solas, como en son de secreto, porque siempre tienen miedo que la mamá se entere. Y en el caso de los varones, también acuden solos pero ellos saben que no van a ser castigados, tal vez les den algún sermón como dicen ellos, pero no les van a castigar de la misma manera que son castigadas

$$
\text { las niñas..." (EP4). }
$$

[15] “...pero si en casa no se hablan entonces viene los experimentos en la calle, viene a preguntarle a un amigo a una amiga, alguien que a lo mejor sabe menos que tú y ahi es donde vienen los problemas" (EP8).

[17] “...porque ellos más que todo, manejan la información con los amigos, o mejores amigos, o con el Internet, pero pocas veces hablan estas cosas con los padres, les he preguntado y ninguno me ha dicho que el papá le enseñó a ponerse el condón, que eso es terrible que pase" (EP7).

(continua) 


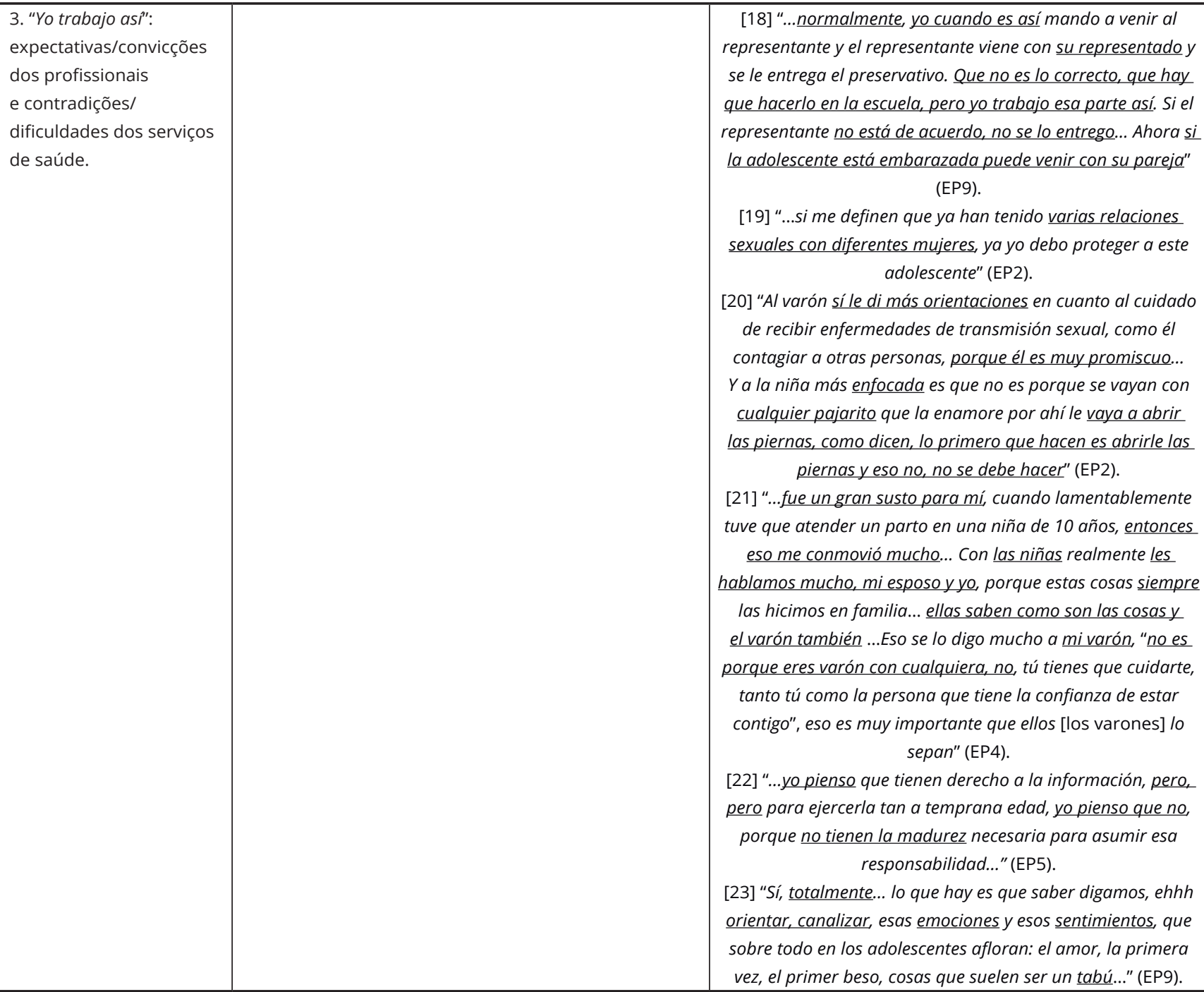

[18] “...normalmente, yo cuando es así mando a venir al representante y el representante viene con su representado y se le entrega el preservativo. Que no es lo correcto, que hay que hacerlo en la escuela, pero yo trabajo esa parte así. Si el representante no está de acuerdo, no se lo entrego... Ahora si la adolescente está embarazada puede venir con su pareja" (EP9).

[19] “...si me definen que ya han tenido varias relaciones sexuales con diferentes mujeres, ya yo debo proteger a este adolescente" (EP2).

[20] "Al varón sí le di más orientaciones en cuanto al cuidado de recibir enfermedades de transmisión sexual, como él contagiar a otras personas, porque él es muy promiscuo... Y a la niña más enfocada es que no es porque se vayan con cualquier pajarito que la enamore por ahí le vaya a abrir las piernas, como dicen, lo primero que hacen es abrirle las piernas y eso no, no se debe hacer" (EP2).

[21] "...fue un gran susto para mí cuando lamentablemente tuve que atender un parto en una niña de 10 años, entonces eso me conmovió mucho... Con las niñas realmente les hablamos mucho, mi esposo y yo, porque estas cosas siempre las hicimos en familia... ellas saben como son las cosas y el varón también. ...Eso se lo digo mucho a mi varón, "no es porque eres varón con cualquiera, no, tú tienes que cuidarte, tanto tú como la persona que tiene la confianza de estar contigo", eso es muy importante que ellos [los varones] 10 sepan" (EP4).

[22] “...yo pienso que tienen derecho a la información, pero, pero para ejercerla tan a temprana edad, yo pienso que no, porque no tienen la madurez necesaria para asumir esa responsabilidad..." (EP5).

[23] "Sí, totalmente... lo que hay es que saber digamos, ehhh orientar, canalizar esas emociones y esos sentimientos, que sobre todo en los adolescentes afloran: el amor, la primera vez, el primer beso, cosas que suelen ser un tabú..." (EP9).

Fonte: a partir dos resultados da investigação.

\section{Sexualidade das/dos adolescentes: um tabu que (re)produz desigualdades no acesso à informação em saúde sexual e reprodutiva}

O termo tabu é utilizado para referir-se ao conjunto de valores, comportamentos e atitudes opostos ao que é socialmente aceitável. O tabu constitui o que está proibido dizer ou fazer em uma sociedade, porque contraria as normas tradicionais/hegemônicas (sociais, religiosas, políticas, entre outras) 16 . Na sociedade contemporânea, a repressão sexual é uma forma de expressão do tabu 16,17. Por um lado, existe uma concepção banalizada do sexo, como produto de mercado e de outro, instituições (famílias/escolas/serviços de saúde) que lidam com a sexualidade com repressão.

A sexualidade na adolescência (e temas relacionados) representam um tabu que: operam criando barreiras para silenciar os canais de comunicação entre as/os adolescentes e os adultos (pais/professores/profissionais de saúde) 18,19; geram formas de castigo/punição para corrigir comportamentos 
questionados (por exemplo, orientações sexuais diferentes das aceitas) $16 \mathrm{em}$ que a transgressão do que é proibido pode ter um alto custo diferenciado para meninas e meninos 18,20,21,22; (re)produzem desigualdades de gênero e reforçam as normas restritivas de gênero 20 .

No Trecho 1, o termo tabu representa a omissão/silêncio dos pais. A/o adolescente fala sobre a falta de comunicação na família e se inclui como afetada/o ao dizer "não te comunicam". Exemplifica como outros atores (médicos) esclarecem dúvidas que não podem ser discutidas com os pais. O pronome "qualquer" indica que com os médicos eles podem falar abertamente. O diálogo sobre sexualidade entre pais e adolescentes geralmente é restrito e afetado pelo "mito do conhecimento" segundo o qual falar sobre sexo e fornecer informações incitam a iniciação sexual precoce 18,19,23. Também a própria forma como os pais passaram da adolescência à vida adulta, muitas vezes desinformados e reprimidos, transmite-se de geração em geração $18,19,24$.

Os fragmentos discursivos nos Trechos 2 e 3 retratam como o tabu opera nas famílias de forma diferenciada entre meninos e meninas, criando fortes barreiras no acesso das meninas à informação referente ao exercício da sexualidade. Os enunciados dos profissionais mostram que as meninas não têm a mesma oportunidade de receber informação sobre saúde sexual e reprodutiva 23 .

No Trecho 2, as três negações são usadas para reafirmar o sentido taxativo da afirmação. A interjeição "juju!" é utilizada como confirmação, expressão de desconfiança ou ironia sobre uma situação. A última mostra-se no Trecho, exemplificando um fato que surpreende: "a mãe busca a camisinha para o filho". O profissional destaca o papel da mãe e como as relações mãe-filho e mãe-filha aparecem com sentidos claramente diferenciados. As filhas são excluídas da informação, tanto em casa quanto na unidade de saúde, mesmo o profissional ofertando o serviço. Há uma moralidade social vigente que condena a iniciação sexual feminina na adolescência e, por outro lado, estimula e legitima a masculina 19,25. No final do Trecho 2, há uma sensação de impotência/dificuldade do profissional em lidar com a reprodução dos privilégios numa sociedade patriarcal.

$\mathrm{Na}$ Venezuela, entre as classes populares prevalece o modelo de família matricentrada inserida numa sociedade patriarcal 10,26. A mãe é a figura central - o eixo da família - embora o homem continue ocupando a posição de poder 10. A mãe estabelece pautas diferenciadas de ensino-aprendizado com os filhos segundo o sexo. Este é um mecanismo para neutralizar a presença predominante do modelo materno e seus componentes femininos no processo de identificação sexual do rapaz 26 . A mãe geralmente assume a maior responsabilidade na criação das/dos filhas/filhos 26 e, portanto, na transmissão de informação sobre sexualidade.

O profissional no Trecho 3 é o único que identifica o tabu como uma das maiores barreiras ao acesso à informação, utilizando o superlativo "malíssimo" e o adjetivo "alarmante" para destacar a gravidade da situação, demonstrando que o tabu constitui uma barreira de gênero. Ao falar na primeira pessoa "una barrera que yo la he visto", ressalta a importância do tema para ele. Também utiliza o recurso de interdiscursividade direta da fala de uma mãe em dois momentos: para reafirmar o inquestionável de seu enunciado e a frustração ao ter que lidar com essa situação. O adjetivo "normal" aparece no enunciado para contrapor duas ideias: a sexualidade como parte da vida humana e a naturalização das normas e crenças de gênero que restringem o direito das adolescentes de se iniciarem sexualmente nesta idade, pois devem manter-se virgens 20,22,24.

As enunciações discursivas das/dos adolescentes reconhecem a existência das desigualdades de gênero ao falar sobre sexualidade nas famílias. No Trecho 4 , o adolescente refere que os rapazes recebem "informação adequada". No entanto, ao falar sobre as meninas, somente utiliza o verbo "dar" como indicativo de que a informação é oferecida, sem qualificá-la. No Trecho 5, mostra-se a naturalização nas famílias de que "é melhor" que o rapaz inicie sua vida sexual cedo, ao contrário das meninas, reforçando a hierarquia de poder e os privilégios do masculino sobre o feminino 18,20,21,24. O "deveria ser" seguido do "igualitário" representam uma forma amena de dizer que não concorda com esse preconceito que inferioriza as meninas, ao excluí-las do direito a exercerem sua sexualidade. $\mathrm{O}$ segundo "pois", que une duas orações, confirma a posição a favor da igualdade (a decisão de ter ou não relações sexuais é tomada por meninas/meninos, independentemente do consentimento dos pais). No tocante aos direitos sexuais, tal aspecto é sumamente importante, porque refere ao direito que as/os adolescentes têm de exercer uma sexualidade plena e responsável 8,23,27. Este enunciado representa uma proposta de desconstrução do discurso hegemônico que promove a segregação sexual para preservar a sexualidade das meninas 28 . 
Os enunciados das adolescentes têm um tom mais questionador já que elas vivenciam cotidianamente a discriminação. O Trecho 6 aponta como as famílias e instituições (educativas/saúde) privilegiam a informação sobre os preservativos para os homens, utilizando "sempre" e repetindo duas vezes "pal hombre" para assinalar que todas as ações são dirigidas para eles. Ao falar na primeira pessoa, a adolescente deixa claro que a proposta de que as meninas sejam consideradas, é dela. A metáfora de ter "un as bajo la manga" denota que as meninas necessitam lançar mão de alguma estratégia oculta para proteger-se no momento de ter relações sexuais, caso o parceiro não esteja preparado. Reflete como precisam desse recurso para exercer sua sexualidade de forma responsável. Isso está relacionado com as dificuldades próprias do sistema de saúde: a baixa promoção e oferta do preservativo feminino nos serviços 9 . Em termos regionais, as disparidades de gênero afetam sobremaneira a saúde sexual e reprodutiva da população adolescente, refletindo, entre outros pontos, na dificuldade de acesso à informação, aos preservativos e outros insumos de contracepção 9,23.

O verbo "tratar" no Trecho 7 indica ao mesmo tempo, proteção e controle, que os pais têm em relação às filhas. Nesse "trato", o que primeiro emerge é a proibição de ter relações sexuais, que pode se seguir da consequência mais temida pela família, a gravidez. A proibição não representa proteção, mas explicita que a opinião das meninas não é considerada. Destaca como os meninos gozam de mais "liberdade" e independência. A frase "sin saber que se está cometiendo un error" frisa uma ação presente diariamente, que a adolescente julga como um erro porque discrimina as meninas. Para enfatizar o categórico do enunciado, são utilizados os verbos proibir e excluir, que denunciam como as meninas são expropriadas de sua autonomia sexual 19,29.

O "trato" diferenciado para meninos e meninas reforça a desigualdade de gênero na experimentação e aprendizado da sexualidade. Para a família, os rapazes terem relações sexuais representa uma comprovação social de sua virilidade, o domínio sobre as mulheres e a conquista do espaço público adulto. Parece que a autonomia sexual feminina não deve ser estimulada, de acordo com os padrões morais vigentes 20,28. A ideia do sexual double standard 21, que considera a existência de normas culturais distintas sobre sexualidade masculina e feminina, e sobre papéis de gênero, incluindo padrões de comportamento que marcam a diferença de poder, estão presentes na sociedade venezuelana, como em outros países da América Latina e Caribe 21,29, naturalizadas pela maioria das famílias e profissionais de saúde. O sexual double standard, ao permitir socialmente que homens tenham mais liberdade sexual que mulheres, acaba por restringir o acesso à informação e a serviços de saúde voltados para a saúde sexual e reprodutiva 20.

"Yo no quiero venir con mi mamá": estratégias das/dos adolescentes para ter acesso à informação sobre saúde sexual e reprodutiva

Segundo a Organização Mundial da Saúde (OMS), alguns grupos de adolescentes "são especialmente vulneráveis, porque sofrem maior exposição aos riscos para a saúde. Eles geralmente têm menos acesso aos serviços de saúde, piores resultados de saúde e mais consequências sociais adversas como resultado da saúde precária" 30 (p. 18). São representados, por exemplo: pelos estigmatizados/marginalizados por causa de orientação sexual, identidade de gênero ou etnia; pelos que vivem em contextos humanitários e frágeis; pelos que não estão na escola, empregados ou em treinamento; entre outros 30 . Na Venezuela, tais grupos podem enfrentar "dificuldades para o exercício de uma sexualidade responsável, devido aos índices de rejeição, exclusão social e violência a que são submetidos” 4 (p. 10).

Desse modo, as adolescentes buscam estratégias para fugir das normas impostas e ter acesso à informação sobre saúde sexual e reprodutiva, especialmente as dos estratos sociais mais altos. No Trecho 8, o profissional reforça a presença constante do tabu em relação às meninas. Fala em primeira pessoa e se vale do recurso de interdiscursividade direta para exemplificar uma das estratégias utilizadas pelas adolescentes: "mentir à mãe" para ocultar que estão procurando informação sobre saúde sexual e reprodutiva e pelo medo de revelar que já se iniciaram sexualmente. Para isto, procuram um serviço público em que possam ser atendidas sem a presença de um adulto, geralmente em uma comunidade diferente de sua residência, com vistas a garantir o sigilo e a confidencialidade no atendimento. O advérbio "incluso" destaca ainda que a situação acontece com meninas maiores de idade. Vale frisar que o artigo 50 da Lei Orgânica para a Proteção de Crianças e Adolescentes garante à/ao 
adolescente, a partir de 15 anos, o direito de receber informações e ter acesso a preservativos, embora os profissionais nem sempre cumpram o estabelecido.

As "perpétuas espirais do poder e prazer" de Foucault 31 (p. 45) emergem nas relações entre pais e filhas/filhos adolescentes e entre profissionais de saúde e adolescentes. Os diversos controles incitam de forma dupla o prazer e o poder: "Prazer em exercer um poder que questiona, fiscaliza, espreita, espia, investiga, apalpa, revela; e por outro lado, prazer que se abrasa por ter que escapar a esse poder, fugir-lhe, enganá-lo ou travesti-lo" 31 (p. 45).

Nesse caso, como em outros países da região, as adolescentes dos estratos sociais mais altos têm maior capacidade de interagir com o sistema de saúde 32, mais opções de acesso à informação de qualidade (nem sempre oferecida pelos pais) e iniciam sua vida sexual com menor probabilidade de ficarem grávidas 27 . Em 2010, um pouco mais de 50\% das adolescentes e jovens venezuelanas que estavam em melhor situação econômica utilizaram um contraceptivo na primeira relação sexual 33 . Já as adolescentes mais pobres, com menor escolaridade, são mais vulneráveis à violência e violações de direitos, suas capacidades são limitadas para interagir com os prestadores de serviços; possuem escassos recursos financeiros para locomover-se até outros estabelecimentos de saúde; podem ser mais estigmatizadas nos serviços e em alguns casos vivenciam a maternidade adolescente como uma alternativa para fugir da família de origem ou como uma questão de menor importância $27,34,35,36$.

Os adolescentes homossexuais são alvo de discriminação nas famílias e nos serviços de saúde, por isso devem utilizar estratégias para ocultar sua identidade sexual e ter acesso à informação sobre saúde sexual e reprodutiva geralmente procurada sob a suspeita de estarem doentes e não por prevenção. Nos Trechos 9 a 12, são assinaladas as dificuldades com as quais eles têm que lidar. No Trecho 9, o advérbio "jamás" denota o categórico/enfático do enunciado do profissional, para assinalar que nunca atendeu a um adolescente homossexual com os pais. A conjunção "ni" aparece duas vezes no enunciado, em frases que denotam negação "ni siquiera; ni le": os adolescentes homossexuais não falam sobre isso com os pais. A homossexualidade ainda é vista em muitos contextos da América Latina e Caribe como enfermidade, pecado ou falta de caráter 37 . A não aceitação dos familiares é categoricamente assinalada no Trecho 10, com a palavra "desquicia", ou seja, o familiar "enlouqueceria" ao saber que o adolescente é homossexual, já que se trata de uma sexualidade dissidente da norma heterossexual 27. Isso implica ausência de garantia dos direitos sexuais das/dos adolescentes pelas instituições, incluindo a família e os serviços de saúde 20.

O profissional do Trecho 11 inicia a oração com "sencillamente" para explicar que deveria ser uma situação simples de entender. Ironiza com a palavra "extraterrestre", para desconstruir a noção de que as/os adolescentes são assexuados 19 . O tom do enunciado é menos direto para mencionar a homossexualidade, que não é qualificada como uma orientação, e sim como "uma parte". O julgamento e a separação nas famílias devido à homossexualidade e o sentido de injustiça envolvido, estão presentes no final do enunciado. As/os adolescentes com orientações sexuais distintas à heterossexual institucionalizada, ao transgredir as normas restritivas de gênero podem ser punidos com sanções e pressões sociais negativas para que se ajustem ao que se consideram os comportamentos adequados, o que pode ter efeitos profundos na saúde mental das/dos adolescentes $25,28,38$. No Trecho 12, destaca-se a questão geracional como uma possível causa para não falar abertamente sobre sexualidade nas famílias 27. O silêncio referido no Trecho 1 aparece novamente como a estratégia que os pais utilizam para não falar com seus filhos sobre temas proibidos como a homossexualidade 19.

O medo do castigo atinge os adolescentes homossexuais (como analisado nos Trechos 9 e 11) e às meninas que não cumprem com as normas estabelecidas (Trechos 8 e 13). O profissional no Trecho 13, fala na primeira pessoa. No início, refere-se às/aos adolescentes e logo enfatiza como o fato de procurar informação, preservativos ou outros contraceptivos no serviço de saúde pode ter consequências diferenciadas que reforçam o sexual double standard 21. Para as meninas, a confidencialidade é fundamental, do contrário poderiam ser punidas. No caso dos meninos/heterossexuais, os castigos são amenizados. Nos serviços de saúde para adolescentes, a preservação ou não do sigilo por parte dos profissionais é considerada como uma forma de exercício de poder 32.

As análises da produção discursiva de adolescentes/profissionais permitem inferir que há um reconhecimento das grandes limitações para falar de saúde sexual e reprodutiva nas famílias, e, de uma educação sexual deficiente 19,35,39. Os Trechos 14 a 17 apontam que as fontes privilegiadas pelas/ pelos adolescentes para esclarecer dúvidas e falar sobre o que não pode ser discutido nas famílias são 
os pares/amigos e a Internet. Para o ano 2013, estimava-se que mais da metade da população adolescente na Venezuela utilizava a Internet diariamente. As atividades mais comuns eram a comunicação pelas redes sociais e a busca por informação ${ }^{40}$. As tecnologias de informação e comunicação trouxeram potencialidades e riscos, uma vez que parte importante da informação sobre sexualidade chega aos adolescentes através da Internet e das redes sociais, e nem sempre é qualificada.

Nos Trechos 14 e 15, observa-se que, em contraposição ao mito do conhecimento, o silêncio ou a proibição incentivam a/o adolescente à busca de informação (mesmo que errada) em outras fontes ou a vivenciar a situação não falada. São utilizados os recursos da interdiscursividade direta e a metáfora do "amigo más avispado [antenado]", para referir-se a uma fonte de informação segura - o amigo mais experiente -, destacando o infalível do conselho "eso no falla" (Trecho 14). Os amigos são uma forte referência de validação e reconhecimento das/dos adolescentes e desempenham um papel expressivo na modelação de condutas 27.

No Trecho 16, enfatiza-se que para as/os adolescentes é mais importante a informação que recebem entre outros jovens 27 . O profissional (Trecho 17) usa o recurso da modalização ao referir que "poucas vezes" as/os adolescentes recebem informação dos pais, enfatiza como a figura paterna pouco se responsabiliza pela transmissão de informação sobre saúde sexual e reprodutiva aos meninos 26 . A família (mãe/pai) é a fonte menos consultada pelos adolescentes.

\section{"Yo trabajo asî": expectativas/convicções dos profissionais e contradições/dificuldades dos serviços de saúde}

A diversidade de critérios para atender às demandas das/dos adolescentes reforça as desigualdades de gênero. Há enunciados que evidenciam as contradições das práticas dos profissionais como reflexo das deficiências do contexto organizacional do sistema de saúde 32,41.

O "normalmente", no Trecho 18, destaca o que é feito com regularidade. O profissional reconhece que os preservativos deveriam ser distribuídos na escola, mas decide trabalhar de outra forma, independentemente do preconizado no PSA. Isso reflete uma contradição no contexto organizacional dos serviços de saúde, em que o profissional pode decidir sobre a entrega dos preservativos, criando barreiras no acesso que afetam meninas e meninos.

As meninas apenas têm acesso aos preservativos se já estão grávidas, independentemente da idade, mas têm que ir com seu parceiro. Se ele não concorda, o acesso pode ser restringido. A proteção das meninas que ainda não engravidaram não aparece no enunciado, apesar do estipulado na Norma Oficial para a Atenção Integral em Saúde Sexual e Reprodutiva 5. Aqui há uma grande diferença de gênero no tratamento dispensado às adolescentes. Do ponto de vista da missão dos serviços de saúde, representa uma contradição porque impede o acesso das meninas a insumos para a prevenção da gravidez e de IST.

$\mathrm{Na}$ América Latina, as adolescentes frequentemente começam a utilizar os contraceptivos após a primeira gravidez, ainda que muitas vezes com uso inconsistente 9,39. Em muitos casos, paradoxalmente, é a maternidade que as ajuda a romper barreiras no acesso à contracepção. Na maioria dos países da América Latina, os protocolos/programas para a prevenção da primeira gravidez são escassos 39. Há limitações no acesso à contracepção de emergência e apenas quatro países (Chile, Colômbia, Equador e Uruguai) possuem leis que o garantem. Na Venezuela, apesar da Norma Oficial para a Atenção Integral em Saúde Sexual e Reprodutiva estabelecer que os contraceptivos de emergência devam ser disponibilizados para as/os adolescentes sexualmente ativos 5, não há oferta suficiente de serviços e são desconhecidos pela maioria das/dos adolescentes. A entrada no universo da maternidade, independentemente da idade, coloca essas meninas em uma nova posição social, ou seja, elas deixam de ser adolescentes para serem mães e, portanto, "adultas". Essa passagem para o mundo adulto pode acarretar uma série de entraves para a vida das meninas como evasão escolar, impedimento na busca por trabalho formal ou ainda vulnerabilidade frente às violências baseadas no gênero 42 .

No Trecho 19, o critério para a entrega do preservativo aos meninos está condicionado ao fato de ter relações sexuais múltiplas: "várias relações sexuais" e "diferentes mulheres". O verbo "dever" na primeira pessoa salienta a ideia da expectativa sobre a sexualidade masculina ativa e o pressuposto da capacidade de prestar atendimento. Refere-se apenas ao rapaz heterossexual ativo sexualmente, sem considerar os não ativos, as meninas e as/os adolescentes homossexuais, embora nas Norma Ofi- 
cial para a Atenção Integral em Saúde Sexual e Reprodutiva 5 sejam incluídos todos aqueles a partir dos 15 anos.

A interação entre as expectativas dos usuários e as dos prestadores influi na aceitabilidade dos serviços de saúde 32,41. Os prestadores, segundo suas convicções, podem demonstrar preconceitos/ imparcialidades em relação a diferentes grupos de usuários 32. A concepção que os profissionais têm sobre a saúde sexual reprodutiva de adolescentes permeia suas práticas nos serviços de saúde. Os de maior abertura ajustarão sua prática e buscarão estratégias para incluir todas/todos as/os adolescentes. Aqueles que não concordam em incluir meninas ou outros grupos, dificilmente irão promovê-la. Há enunciados em que emergem crenças/preconceitos dos profissionais sobre a informação que consideram que deve ser oferecida a meninas/meninos ao falar de seus próprios filhos/filhas, e que podem reforçar as desigualdades de gênero.

No Trecho 20, o profissional, em primeira pessoa do singular ressalta que deu ao filho as "orientações” necessárias para sua proteção, mas, quando se refere à filha, utiliza o verbo "enfocar" para apontar que se concentrou no namoro. A expressão "cualquier pajarito" para indicar que, não importa quem seja o namorado, a filha não deve "abrir las piernas”. Esta forma pejorativa de falar das relações sexuais das meninas mostra uma questão proibida categoricamente com a afirmação isso não deve se fazer, com dois "não" e o uso do verbo "dever". A expressão "como dicen" é uma forma de explicitar que não é ela que diz, é a sociedade.

A experiência relatada pela profissional no início do Trecho 21 a mobilizou, tanto que criou canais de comunicação com as filhas e o filho. O uso do verbo "hemos" na terceira pessoa do plural remete à concepção de família, aparece a figura paterna. A informação oportuna e de qualidade é dada para filhas e filho, e destacada na frase "porque ellas saben cómo son las cosas y el varón también". Trata com respeito as meninas e destaca o cuidado do filho e sua parceira. Esse enunciado representa uma abertura de novas possibilidades e reflexões de descontruir as normas restritivas de gênero 20,38.

No Trecho 22, o profissional, apesar de concordar com o direito das/dos adolescentes de terem informações, com o "pero" nega o direito ao exercício da sexualidade, alegando pouca maturidade das/dos adolescentes 19 . No Trecho 23, os verbos "orientar/canalizar" indicam o papel que os adultos deveriam exercer no acompanhamento das primeiras experiências, ao invés da proibição como uma estratégia para evitar a sexualidade adolescente.

\section{Considerações finais}

Desvendar as barreiras de acesso das/dos adolescentes à informação sobre saúde sexual e reprodutiva implica reconhecer os dispositivos institucionais que atuam na sociedade venezuelana, com maior força nas relações de poder na família, na escola e nos serviços de saúde. Tais barreiras reforçam a ideia do sexual double standard ${ }^{21}$ perpetuando modelos de dominação patriarcal. Sua naturalização possibilita uma reprodução silenciosa de crenças/atitudes sobre os papéis sociais de homens e mulheres 21 , provocando desigualdades de gênero no acesso aos serviços de saúde.

Para garantir o acesso dos adolescentes à informação qualificada sobre saúde sexual e reprodutiva, é preciso entender que este deve ser promovido nos diferentes âmbitos: família, escola e os serviços de saúde 27. É fundamental o trabalho intersetorial entre serviços de saúde, movimentos sociais, ativismo comunitário para otimizar esforços coletivos pela mudança das normas restritivas de gênero 20,23,38. As EBS, além de conhecer e implementar os protocolos definidos pelo PSA, requerem de capacitação permanente para discutir o papel das normas restritivas de gênero presentes nos discursos hegemônicos analisados.

Os sistemas de saúde podem fazer uma diferença na redução das desigualdades de gênero e na restrição das normas de gênero subjacentes que as mantêm 20,23. As estratégias para garantir um acesso equitativo a essa população demandam uma revisão profunda dos processos no atendimento à saúde, reconhecendo o tensionamento entre as convicções das/dos adolescentes/pais e profissionais, como entre adolescentes e pais 32. A aceitabilidade das/dos adolescentes é condicionada pela forma como a família e os serviços de saúde concebem a saúde sexual e reprodutiva. Por vezes, a família pode ser a primeira barreira de acesso, sobretudo em relação às meninas. Mas também a organização dos serviços pode se constituir numa barreira ao não reconhecer em conta os adolescentes como sujeito 
de direitos na sua diversidade, especialmente para grupos mais vulneráveis como as meninas e as/os adolescentes homossexuais.

As mudanças na prestação dos serviços oferecidos para as/os adolescentes envolveriam a renegociação das posições subjetivas tradicionais na interação profissional-usuário e a desconstrução das relações de poder 32 subjacentes na cultura venezuelana. É possível observar, em vários enunciados, propostas de desconstrução dos discursos hegemônicos que fomentam a desigualdade de gênero na saúde. É com participação de novas gerações de adolescentes, profissionais, pais, professores, entre outros, produzindo discursos e normas de gênero mais equitativas, que possíveis mudanças poderão ser engendradas.

\section{Colaboradores}

H. L. Heredia-Martínez participou no levantamento e análise dos dados; desenho do estudo; redação e revisão final do artigo. E. Artmann participou na análise dos dados; desenho do estudo, redação e revisão final do artigo. M. Nascimento participou no desenho do estudo; redação e revisão final do artigo.

\section{Informações adicionais}

ORCID: Henny Luz Heredia-Martínez (0000-00024609-0481); Elizabeth Artmann (0000-0002-86905964); Marcos Nascimento (0000-0002-33634232).

\section{Agradecimentos}

Este trabalho foi realizado com o apoio do Instituto de Altos Estudos “Dr. Arnoldo Gabaldon" do Ministério do Poder Popular para a Saúde da Venezuela; do Programa de Estudantes - Convênio de PósGraduação (PEC-PG), da Capes/CNPq/MRE-Brasil e da Fundação de Amparo à Pesquisa do Estado do Rio de Janeiro (FAPERJ).

\section{Referências}

1. Gupta MD, Engelman R, Levy J, Luchsinger G, Merrick T, Rosen JE. Estado de la población mundial 2014: el poder de 1800 millones. https://www.unfpa.org/sites/default/files/ pub-pdf/SWOP2014\%20Report\%20Web\%20 Spanish.pdf (acessado em 05/Set/2018).

2. Fondo de las Naciones Unidas para la Infancia. Estado Mundial de la Infancia 2016: una oportunidad para cada niño. https://www.unicef. org/spanish/publications/files/UNICEF_ SOWC_2016_Spanish.pdf (acessado em 09/ Set/2018).

3. Fondo de Población de las Naciones Unidas. Estado de la población mundial 2019. https:// www.unfpa.org/sites/default/files/pub-pdf/ UNFPA_PUB_2019_ES_Estado_de_la_Po blacion_Mundial.pdf (acessado em 13/ Set/2019).

4. Ministerio del Poder Popular para la Salud. Directrices prácticas para intensificar la prevención del VIH y otras ITS en Venezuela. https://venezuela.unfpa.org/sites/default/fi les/pub-pdf/Directrices\%20Practicas\%20VIH. pdf (acessado em 04/Set/2018).

5. Ministerio del Poder Popular para la Salud. Norma Oficial para la Atención Integral en Salud Sexual y Reproductiva. https://venezuela. unfpa.org/sites/default/files/pub-pdf/Nor maOficial\%20SSR\%202013_1.pdf (acessado em 10/Set/2018).

6. Instituto Nacional de Estadística. Proyecciones de población. http://www.ine.gov.ve/index. php?option $=$ com_content $\&$ view $=$ category\&id $=98 \&$ Itemid $=51$ (acessado em 20/Set/2018)

7. República Bolivariana de Venezuela. Ley Orgánica para la Protección del Niño y el Adolescente (LOPNNA). Gaceta Oficial de la República de Venezuela 2015; 8 jun.

8. Morlachetti A. Políticas de salud sexual y reproductiva dirigidas a adolescentes y jóvenes: un enfoque fundado en los derechos humanos. https://repositorio.cepal.org/bits tream/handle/11362/12828/np85063095_ es.pdf? sequence $=1 \&$ isAllowed $=y$ (acessado em 10/Set/2018). 
9. Programa Conjunto de las Naciones Unidas sobre el VIH/SIDA; Fondo de Población de las Naciones Unidas; Fondo de las Naciones Unidas para la Infancia. Análisis sobre legislaciones y políticas que afectan el acceso de adolescentes y jóvenes a los servicios de SSR y VIH en América Latina. https://argentina.un fpa.org/sites/default/files/pub-pdf/Analisislegislaciones-SSR-y-VIH_1.pdf (acessado em 10/Set/2018).

10. Programa de Salud Sexual y Reproductiva, Fondo de Población de las Naciones Unidas. Educación de la Sexualidad y Salud Sexual y Reproductiva. Guía para Docentes. https://ve nezuela.unfpa.org/sites/default/files/pub-pdf/ Educacion\%20SSR\%20Guia\%20Docentes.pdf (acessado em 10/Set/2018).

11. Heredia H, Artmann E. Criterios para la (re) distribución equitativa de los equipos básicos de salud en el nivel local en Venezuela. Cad Saúde Pública 2018; 34:e00171117.

12. Organización Mundial de la Salud. Salud de la madre, el recién nacido, del niño y del adolescente. 2017. https://www.who.int/mater nal_child_adolescent/topics/adolescence/es/ (acessado em 12/Set/2019).

13. Minayo MCS. O desafio do conhecimento: pesquisa qualitativa em saúde. São Paulo: Editora Hucitec; 2004.

14. Fairclough N. Teoria social do discurso. In: Fairclough N, organizador. Discurso e mudança social. Brasília: Editora UnB; 2001. p. 89132.

15. Venezuela. Código Penal de Venezuela. Gaceta Oficial de la República de Venezuela 2000; (Extraordinario 5.494) 20 out.

16. Cabral R, Romeiro A. Sobre a sexualidade controlada: poder e repressão sexual em Michel Foucault. Educação, Batatais 2011; 1:87-106.

17. Chaui MS. Repressão sexual: essa nossa (des) conhecida. São Paulo: Editora Brasiliense; 1991.

18. Sousa LB, Fernandes JFP, Barroso MGT. Sexualidade na adolescência: análise da influência de fatores culturais presentes no contexto familiar. Acta Paul Enferm 2006; 19:408-13.

19. Correa C, Cubillán F. Manual de capacitación salud sexual y reproductiva: desde una mirada de género. Maracay: Instituto de Altos Estudios "Dr. Arnoldo Gabaldon"; 2009.

20. Heise L, Greene ME, Opper N, Stavropoulou M, Harper C, Nascimento M, et al. Gender inequality and restrictive gender norms: framing the challenges to health. Lancet 2019; 393:2440-54.

21. Lefkowitz ES, Shearer CL, Gillen MM, Espinosa-Hernandez G. How gendered attitudes relate to women's and men's sexual behaviors and beliefs. Sex Cult 2014; 18:833-46.

22. Espinosa-Hernández G, Bissell-Havran J, Nunn A. The role of religiousness and gender in sexuality among Mexican adolescents. J Sex Res 2015 2015; 52:887-97.
23. Svanemyr J, Amin A, Robles OJ, Greene ME. Creating an enabling environment for adolescent sexual and reproductive health: a framework and promising approaches. J Adolesc Health 2015; 56 Suppl 1:7-14.

24. De Godoy Martins C, De Almeida FM, Alencastro LC, De Matos K, De Souza S. Sexualidade na adolescência: mitos e tabus. Ciênc Enferm 2012; 18:25-37.

25. World Health Organization. What about boys? A literature review on the health and development of adolescent boys. https://apps.who.int/ iris/bitstream/handle/10665/66487/WHO_ FCH_CAH_00.7.pdf;jsessionid=2D804976C 032AE5CEAE1A59ED2541D09? sequence $=1$ (acessado em 30/Ago/2019).

26. Moreno A. La familia popular venezolana. 2a Ed. Caracas: Centro de Investigaciones Populares Caracas, Fundación Centro Gumilla;1997.

27. Heilborn ML. Por uma agenda positiva dos direitos sexuais da adolescência. Psicol Clín 2012; 24:57-68.

28. Blum RW, Mmari K, Moreau C. It begins at 10: how gender expectations shape early adolescence around the world. J Adolesc Health 2017; 61 Suppl 4:3-4.

29. Ferrari W, Peres S, Nascimento M. Experimentação e aprendizagem na trajetória afetiva e sexual de jovens de uma favela do Rio de Janeiro, Brasil, com experiência de aborto clandestino. Ciênc Saúde Colet 2018; 23:2937-50.

30. Global Accelerated Acton for the Health of Adolescents (AA-HA!): guidance to support country implementaton. Geneva: World Health Organizaton; 2017. https://apps.who.int/iris/bitstream/han dle/10665/255415/9789241512343-eng. pdf? sequence $=1$ (acessado em 01/Set/2019).

31. Foucault M. História da sexualidade I: a vontade de saber. Rio de Janeiro: Edições Graal; 1988.

32. Gilson L. Aceitabilidade, confiança e equidade. In: McIntyre D, Mooney G, organizadores. Aspectos econômicos da equidade em saúde. Rio de Janeiro: Editora Fiocruz; 2014. p. 163-90.

33. Instituto Nacional de Estadísticas. Resultados de la Encuesta Demográfica de Venezuela ENDEVE 2010. Caracas: Fondo de Población de las Naciones Unidas; 2013. https:// venezuela.unfpa.org/es/publications/resul tados-de-la-encuesta-demogr\%C3\%A1ficade-venezuela-endeve-2010 (acessado em 15/ Set/2018)

34. Fondo de Población de las Naciones Unidas. Prevención del embarazo adolescente: una mirada completa Bolivia, Chile, Colombia, Ecuador, Perú y Venezuela. http:// www.codajic.org/sites/www.codajic.org/ files/Embarazo\%20Adolescente\%20\%20 Medell\%C3\%Adn\%202011.pdf (acessado em 15/Set/2018). 
35. Fondo de Población de las Naciones Unidas. Estado de la población mundial 2013: maternidad en la niñez. Enfrentar el reto del embarazo en adolescentes. https://www.unfpa.org/sites/ default/files/pub-pdf/ES-SWOP2013.pdf (acessado em 15/Set/2018).

36. Cancino AMM, Valencia MH. Embarazo en la adolescencia: cómo ocurre en la sociedad actual. Perinatol Reprod Humana 2015; 29:76-82.

37. Gómez MM. Violencia, homofobia y psicoanálisis: entre lo secreto y lo público. Revista de Estudios Sociales 2007; 28:72-85.

38. Weber AM, Cislaghi B, Meausoone V, Abdalla S, Mejía-Guevara I, Loftus P, et al. Gender norms and health: insights from global survey data. Lancet 2019; 393:2455-68.

39. Rodríguez J. La reproducción en la adolescencia en América Latina: viejas y nuevas vulnerabilidades. Realidad, datos y espacio. Revista Internacional de Estadística y Geografía 2012; 3:66-81.
40. Freitez A, Correa G, Di Brienza M, Fernández J, Ponce M, Zúñiga G. Proyecto Encuesta Nacional de Juventud 2013 (ENJUVE 2013-UCAB). Caracas: Instituto de Investigaciones Económicas y Sociales de la Universidad Católica Andrés Bello; 2013. http:// proyectojuventud.ucab.edu.ve/wp-content/ uploads/2014/07/Resumen-para-la-prensa. pdf (acessado em 03/Set2019).

41. Thiede M, Akweongo P, Di Mclntyre. Explorando as Dimensões do Acesso. In: Di McIntyre, Mooney G, organizadores. Aspectos econômicos da equidade em saúde. Rio de Janeiro: Editora Fiocruz; 2014. p. 137-61.

42. Vaitla B, Taylor AY, Horn JV, Cislaghi B. Social norms and girls' well-being: linking theory and practice. Washington DC: Data2X; 2017. 


\section{Abstract}

The objective was to analyze the discourses of adolescents and health professionals in a state of Venezuela concerning this age group's access to information on sexual and reproductive health. Interviews were conducted with 12 adolescents and 12 health professionals and processed with Fairclough's Critical Discourse Analysis. The results were structured in three themes: gender inequalities; strategies used by adolescents; and difficulties in the health services. The arguments revealed that matricentric family culture limits girls' access to information on sexual health. Greater effort is required of girls and homosexual adolescents to access information. Both of them seek health services outside their area of residence, due to fear of the family or lack of trust in professional secrecy. The prime sources for adolescents to information are friends and the Internet. One of the main challenges is to recognize the institutional devices acting in Venezuelan society, with greater force in power relations in the family, school, and health services. Such barriers reinforce the "sexual double standard", perpetuating models of patriarchal domination. The naturalization of such models allows the silent reproduction of beliefs and attitudes, causing gender inequalities in access to health services. Changes in the provision of services offered to adolescents involve renegotiation of traditional subjective positions in user-provider interaction and deconstruction of gender relations. Possible changes will be engendered with participation by new generations of adolescents, health professionals, parents, and teachers, producing more equitable gender discourses and norms.

Adolescent; Gender Identify; Health Services; Equity in Access to Health Services; Sexual Health

\section{Resumen}

El objetivo fue analizar los discursos de adolescentes y profesionales de salud, en un estado de Venezuela, sobre el acceso de esta población a la información sobre salud sexual y reproductiva. Se realizaron 12 entrevistas con adolescentes $y$ 12 con profesionales, trabajadas con Análisis del Discurso Crítico de Fairclough. Los resultados se estructuraron en 3 temas: desigualdades de género; estrategias utilizadas por los adolescentes y dificultades de los servicios de salud. En los argumentos identificados se observa que la cultura de las familias matricentradas limita el acceso de las niñas a la información sobre salud sexual. De las niñas y de los adolescentes homosexuales se exige mayor esfuerzo en el acceso a la información. Ambos grupos buscaron servicios fuera de su área de residencia por temor a la familia o por no confiar en el secreto profesional. Las fuentes privilegiadas por los adolescentes para obtener información son: amigos e Internet. Uno de los principales desafíos es reconocer los dispositivos institucionales que actúan en la sociedad venezolana, con mayor fuerza en las relaciones de poder en la familia, en la escuela y servicios de salud. Tales barreras refuerzan el sexual double standard, perpetuando modelos de dominación patriarcal. Su naturalización posibilita una reproducción silenciosa de creencias/actitudes, provocando desigualdades de género en el acceso a los servicios de salud. Los cambios en la prestación de los servicios ofrecidos para adolescentes implicarían la renegociación de las posiciones subjetivas tradicionales en la interacción profesional-usuario y la deconstrucción de las relaciones de poder. Es con la participación de nuevas generaciones de adolescentes, profesionales, padres, profesores, produciendo discursos y normas de género más equitativas, que posibles cambios serán generados.

Adolescente; Identidad de Género; Servicios de Salud; Equidad em el Acceso a los Servicios de Salud; Salud Sexual
Recebido em 06/Out/2018

Versão final reapresentada em 19/Set/2019

Aprovado em 07/Out/2019 